\title{
ENDOTHELIAL AND NON-ENDOTHELIAL CORONARY BLOOD FLOW RESERVE AND LEFT VENTRICULAR DYSFUNCTION IN SYSTEMIC HYPERTENSION
}

\author{
Aloísio Marchi Rocha, ${ }^{\mathrm{I}}$ Vera Maria Cury Salemi, ${ }^{\mathrm{I}}$ Pedro Alves Lemos Neto, ${ }^{\mathrm{II}}$ \\ Afonso Yoshikiro Matsumoto, ${ }^{\mathrm{I}}$ Valéria Fontenelle Angelim Pereira, ${ }^{\mathrm{I}}$ Fábio \\ Fernandes, ${ }^{\text {I Luciano Nastari, }}$, Charles Mady ${ }^{\mathrm{I}}$
}

doi: $10.1590 / \mathbf{S 1 8 0 7 - 5 9 3 2 2 0 0 9 0 0 0 4 0 0 0 1 1}$

Rocha AM, Salemi VMC, Neto PAL, Matsumoto AY, Pereira VFA, Fernandes F, Nastari L, Mady C. Endothelial and non-endothelial coronary blood flow reserve and left ventricular dysfunction in systemic hypertension. Clinics. 2009;64(4):327-35

OBJECTIVES: We evaluated the impairment of endothelium-dependent and endothelium-independent coronary blood flow reserve after administration of intracoronary acetylcholine and adenosine, and its association with hypertensive cardiac disease.

INTRODUCTION: Coronary blood flow reserve reduction has been proposed as a mechanism for the progression of compensated left ventricular hypertrophy to ventricular dysfunction.

METHODS: Eighteen hypertensive patients with normal epicardial coronary arteries on angiography were divided into two groups according to left ventricular fractional shortening (FS). Group 1 ( $F S \geq 0.25$ ): $\mathrm{n}=8, \mathrm{FS}=0.29 \pm 0.03$; Group 2 ( $\mathrm{FS}<0.25$ ): $\mathrm{n}=10, \mathrm{FS}=$ $0.17 \pm 0.03$.

RESULTS: Baseline coronary blood flow was similar in both groups (Group 1: $80.15 \pm 26.41 \mathrm{~mL} / \mathrm{min}$, Group 2: $100.09 \pm 21.51$ $\mathrm{mL} / \mathrm{min}, p=\mathrm{NS}$ ). In response to adenosine, coronary blood flow increased to $265.1 \pm 100.2 \mathrm{~mL} / \mathrm{min}$ in Group 1 and to $300.8 \pm 113.6$ $\mathrm{mL} / \mathrm{min}(p<0.05)$ in Group 2. Endothelium-independent coronary blood flow reserve was similar in both groups (Group 1: 3.31 \pm 0.68 and Group 2: $2.97 \pm 0.80, p=\mathrm{NS})$. In response to acetylcholine, coronary blood flow increased to $156.08 \pm 36.79 \mathrm{~mL} / \mathrm{min}$ in Group 1 and to $177.8 \pm 83.6 \mathrm{~mL} / \mathrm{min}$ in Group $2(\mathrm{p}<0.05)$. Endothelium-dependent coronary blood flow reserve was similar in the two groups (Group 1: $2.08 \pm 0.74$ and group Group 2: $1.76 \pm 0.61, \mathrm{p}=\mathrm{NS}$ ). Peak acetylcholine/peak adenosine coronary blood flow response (Group 1: $0.65 \pm 0.27$ and Group 2: $0.60 \pm 0.17$ ) and minimal coronary vascular resistance (Group 1: $0.48 \pm 0.21$ $\mathrm{mmHg} / \mathrm{mL} / \mathrm{min}$ and Group 2: $0.34 \pm 0.12 \mathrm{mmHg} / \mathrm{mL} / \mathrm{min}$ ) were similar in both groups ( $\mathrm{p}=\mathrm{NS}$ ). Casual diastolic blood pressure and end-systolic left ventricular stress were independently associated with FS.

CONCLUSIONS: In our hypertensive patients, endothelium-dependent and endothelium-independent coronary blood flow reserve vasodilator administrations had similar effects in patients with either normal or decreased left ventricular systolic function.

KEYWORDS: Coronary blood flow reserve; Hypertension; Heart failure; Adenosine; Acetylcholine

\section{INTRODUCTION}

Left ventricular hypertrophy (LVH) in the context of systemic hypertension is an independent risk factor for

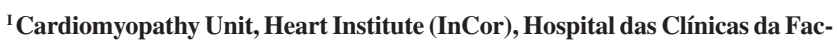
uldade de Medicina da Universidade de São Paulo - São Paulo/SP, Brazil.

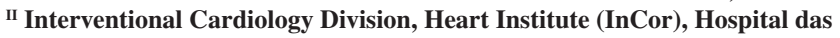
Clínicas da Faculdade de Medicina da Universidade de São Paulo - São Paulo/SP, Brazil.

Email: verasalemi@uol.com.br

Tel.: 55113556.9812

Received for publication on November 10, 2008

Accepted for publication on January 15, 2009 sudden death, ventricular arrhythmia, myocardial ischemia, and heart failure. ${ }^{1}$ Many pathophysiological mechanisms, including reductions in coronary blood flow reserve (CBFR), have been proposed to explain the progression of compensated LVH to ventricular dysfunction. ${ }^{2}$ Coronary microcirculation alterations in hypertension have already been reported in a previous study. ${ }^{3}$ Antony et al. (1993) showed that CBFR was low in hypertensive patients both with and without LVH, but that following one year of antihypertensive treatment, reserve became normal in the non-LVH patients, suggesting that hypertension treatment may normalize compromised coronary blood flow. ${ }^{4}$ 
In patients with normal endothelium-independent CBFR, LV maladaptation as a result of inadequate flow may be explained by the occurrence of coronary vasculature endothelial dysfunction. ${ }^{3}$ This phenomenon has been described in the peripheral and coronary circulation of dilated cardiomyopathy patients. ${ }^{5}$ Endothelial dysfunction in hypertension has been shown in peripheral and coronary vasculature in patients without $\mathrm{LV}$ systolic dysfunction. ${ }^{3,6}$ It is possible that impairment of endothelium-dependent coronary vasodilatation capacity is one of the mechanisms responsible for inadequate myocardial flow, and therefore contributes to ventricular maladaptation before the development of morphological alterations that affect the capacity of endothelium-independent vasodilatation.

Given the multitude of factors involved in LV decompensation, no study to date has determined the roles of endothelium-dependent and independent coronary reserve compromise in different grades of hypertensive heart disease.

The goals of this study were: (1) to evaluate endotheliumdependent and independent coronary artery vasodilatation compromise in hypertensive patients with reduced or preserved fractional shortening; (2) to evaluate whether an association exists between LV dysfunction progression and endotheliumdependent and independent coronary reserve decrease; (3) to evaluate the influence of clinical, structural, and functional factors to LV maladaptation in hypertensive patients.

\section{METHODS}

\section{Study population and groups}

At our institution, 33 hypertensive patients underwent clinical evaluation and additional routine laboratory examinations, 12-lead electrocardiography, chest X-ray, and transthoracic echocardiography. All patients were in NYHA functional class I or II, and the initial evaluation was performed using conventional antihypertensive medication.

Inclusion criteria were based on hypertension history, blood pressure (BP) levels above $140 \mathrm{X} 90 \mathrm{~mm} \mathrm{Hg}$ recorded on at least three occasions with the patient in a sitting position after resting for at least 5 minutes. ${ }^{7}$ Exclusion criteria were serum creatinine $>2.0 \mathrm{mg} / \mathrm{dL}$; presence of coronary artery stenosis $>30 \%$; contraindication for adenosine (previous chronic obstructive pulmonary disease, use of xanthine, bradyarrhythmia) or femoral access catheterization; iodate contrast allergy; use of acetylsalicylic acid, which could interfere with the behavior of coronary blood flow ${ }^{8}$ and the presence of any other systemic or heart disease.

From the initial selected population, 12 patients were excluded due to significant coronary artery disease and three others were excluded due our inability to obtain an adequate coronary flow curve. Therefore, 18 patients were studied, divided into 2 groups based on left ventricular fractional shortening (LVFS). Group 1 exhibited preserved ventricular function and LVFS $\geq 25 \%$, and Group 2 exhibited ventricular dysfunction and LVFS $<25 \%$. Group 1 comprised 8 patients ( 3 male, $50.88 \pm 14.65$ years). Group 2 comprised 10 patients ( 7 male, $48.7 \pm 12.45$ years). Baseline characteristics of the two groups are shown in Table 1. Patients from Group 1 were treated with hydrochlorothiazide $(50 \mathrm{mg} /$ day), methyldopa (750-1500 mg/day), amlodipine (10 mg/day), angiotensin conversion enzyme inhibitors (captopril 100-150 mg/day or enalapril $40 \mathrm{mg} /$ day) or angiotensin receptor blocker (losartan 25-100 mg/day). Group 2 patients were treated with hydrochlorothiazide (50 mg/day), methyldopa (750$1500 \mathrm{mg} /$ day), clonidine $(0.2 \mathrm{mg} /$ day $)$, nifedipine $(60 \mathrm{mg} /$ day), angiotensin conversion enzyme inhibitors (captopril

Table 1 - Baseline characteristics of the two groups of patients

\begin{tabular}{|c|c|c|c|}
\hline & Group 1 & Group 2 & P value \\
\hline Number of patients & $\mathrm{n}=8$ & $\mathrm{~N}=10$ & \\
\hline Age (years) & $50.88 \pm 14.65$ & $48.7 \pm 12.45$ & 0.7377 \\
\hline Male & $3 / 8(37.5 \%)$ & $7 / 10(70 \%)$ & 0.3416 \\
\hline \multirow[t]{2}{*}{ Race } & 4 Caucasians $(50 \%)$ & 3 Caucasians $(30 \%)$ & \\
\hline & 4 Afro-americans $(50 \%)$ & 6 Afro-americans $(70 \%)$ & 0.3441 \\
\hline Body surface area $\left(\mathrm{m}^{2}\right)$ & $1.68 \pm 0.13$ & $1.60 \pm 0.20$ & 0.3640 \\
\hline Total cholesterol (mg/dL) & $191.63 \pm 27.00$ & $184.80 \pm 19.94$ & 0.5455 \\
\hline LDL-cholesterol (mg/dL) & $123.63 \pm 17.74$ & $114.00 \pm 25.18$ & 0.3750 \\
\hline HDL-cholesterol (mg/dL) & $48.75 \pm 12.87$ & $46.20 \pm 15.65$ & 0.7157 \\
\hline Triglycerides (mg/dL) & $97.00 \pm 20.81$ & $123.00 \pm 110.98$ & 0.7223 \\
\hline Glucose (mg/dL) & $99.00 \pm 6.76$ & $96.10 \pm 12.07$ & 0.5533 \\
\hline Urea $(\mathrm{mg} / \mathrm{dL})$ & $31.25 \pm 7.59$ & $40.60 \pm 8.72$ & 0.0295 \\
\hline Creatinine $(\mathrm{mg} / \mathrm{dL})$ & $0.94 \pm 0.14$ & $1.13 \pm 0.23$ & 0.0558 \\
\hline Hemoglobin (g/dL) & $13.68 \pm 0.78$ & $13.53 \pm 0.79$ & 0.7023 \\
\hline Hematocrit $(\%)$ & $40.25 \pm 1.49$ & $40.60 \pm 2.55$ & 0.4383 \\
\hline Sodium $(\mathrm{mEq} / \mathrm{L})$ & $140.38 \pm 1.41$ & $138.80 \pm 2.25$ & 0.1043 \\
\hline$\underline{\text { Potassium }(\mathrm{mEq} / \mathrm{L})}$ & $4.04 \pm 0.49$ & $4.25 \pm 0.31$ & 0.2778 \\
\hline
\end{tabular}


$150 \mathrm{mg} /$ day or enalapril $10-40 \mathrm{mg} /$ day $)$, digoxin $(0.25 \mathrm{mg} /$ day), furosemide (40-80 mg/day), and spironolactone (25$100 \mathrm{mg} /$ day).

All patients had been diagnosed with hypertension at least 4 years prior to our study, and had been receiving initial antihypertensive treatment for at least 3.5 years.

Our hospital's ethics committee approved this study protocol, \# 696/00, and patients signed an informed consent form, in compliance with ethics committee guidelines.

\section{Echocardiography study}

To determine LV structure and function, an echocardiographic study was performed, and the following parameters were determined according to American Society of Echocardiography recommendations: ${ }^{9} \mathrm{LV}$ end-diastolic diameter (LVDD), LV end-systolic diameter (LVSD), interventricular septum (IVS), and posterior wall (PW) systolic and diastolic thickness. The equipment used was an ACUSON Sequoia 512 model (Acuson Corporation, Mountain View, California, EUA) equipped with a multifrequency transducer, model 3V2c.

We calculated LV mass corrected by body surface area (BSA) to obtain LV mass index (LVM) ${ }^{10}$ LVEF relative wall thickness (RWT). ${ }^{9}$ and LV end-systolic stress (LVFSS) were also studied. ${ }^{11}$

\section{Hemodynamic study}

Patients underwent right cardiac catheterization performed by the thermodilution method using a Swan-Ganz catheter, model $139 \mathrm{f} 75$ (Baxter Healthcare Corporation, Irvine, CA, USA) for pressure and cardiac output measurements. ${ }^{12}$ To measure LV aorta pressure, left cardiac catheterization was performed with cinecoronariography using non-ionic iopamidol iodated contrast (Iopamiron 370, Schering do Brasil, Química e Farmacêutica Ltda), and an intracoronary Doppler blood flow study. No left ventriculography was performed, in order to decrease the contrast dosage. Patients with significant coronary obstruction $(>30 \%)$ did not undergo the coronary blood flow study.

Antihypertensive medication and vasodilative drugs were withheld for 24 to 48 hours before the study. Patients were advised to avoid eating and taking medications containing xanthines, due to the inhibiting effect these substances have on adenosine.

\section{Coronary arterial flow study}

Following the hemodynamic and cinecoronariography study, a dose of 10,000 UI heparin was administered by IV bolus. Afterward, a 6F or 7F (Boston Scientific Scimed, Inc., Maple Grove, MN, USA) catheter guide was positioned in the left coronary artery ostium. A 0.014-inch FloWire model guide wire (Cardiometrics, Inc., Mountain View, CA) with a FloMap model Doppler transducer (Cardiometrics, Inc., Mountain View, CA) on its extremity was introduced through the catheter and positioned in the proximal third of the anterior descending artery.

The following variables were evaluated: epicardial luminal cross-sectional area (CSA) at the location where flow velocity was measured, and coronary blood flow $(\mathrm{CBF})^{13}$ Endothelium-independent hyperemia induction was performed with adenosine (Adenocard, Libbs Farmacêutica

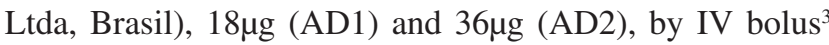
Next, angiography was performed to determine crosssectional diameter under these conditions to calculate $\mathrm{CBF}$ with AD1 and AD2. The greatest flow obtained (CBFRm ad) was used to calculate coronary blood flow reserve (CBFR), according to the formula:

\section{CBFRe $\mathrm{i}=\mathrm{CBFRm}$ ad/CBFRb}

where: CBFRe-i = coronary blood flow reserve endotheliumindependent; CBFRm ad = maximum coronary blood flow reserve with adenosine; $\mathrm{CBFRb}=$ coronary blood flow reserve baseline.

Acetylcholine was administered at a velocity of $5 \mathrm{~mL} /$ min for 2 minutes, with target concentrations of $10^{-7}$ (AC1), $10^{-6}$ (AC2), and $10^{-5} \mathrm{M}$ (AC3) [14]. The endotheliumdependent CBFR was calculated according to the formula:

\section{CFRed $=$ CBFRm ac/CBFRb}

where: CBFRe $\mathrm{i}=$ endothelium-dependent coronary blood flow reserve; $\mathrm{CBFRm}$ ac $=$ maximum coronary arterial flow reserve with acetylcholine; $\mathrm{CBFRb}=$ coronary blood flow reserve baseline.

In order to evaluate whether infusion through acetylcholine dilution could increase flow due to shear stress, the acetylcholine study was preceded by a saline infusion at $5 \mathrm{~mL} / \mathrm{min}$ velocity for 2 minutes. ${ }^{6}$ To evaluate the extent of endothelium-dependent coronary vasodilation, the highest CBF obtained with acetylcholine (CBFRm ac) was divided by the highest $\mathrm{CBF}$ obtained with adenosine (CBFRm ad). ${ }^{3}$

Minimal coronary vascular resistance (RESISTmin) was calculated by evaluating the ratio between mean blood pressure (MBP ad) and maximum coronary blood flow using adenosine..$^{3,8}$

At the end of the procedure, a $300 \mu \mathrm{g}$ nitroglycerin dose (Tridil, Cristália Produtos Químicos Farmacêuticos Ltda, 
Brazil) was administered by IV bolus with the patient at baseline to evaluate endothelium-independent vasodilation capacity of the anterior descending coronary artery. Two minutes later, angiography was performed to determine the cross-sectional diameter under these conditions and the time necessary to achieve maximum epicardial artery dilation. ${ }^{3}$

\section{Statistical analysis}

Groups 1 and 2 were compared using a Student $t$ test or a Wilcoxon's test for independent samples in relation to continuous variables evaluated at one time, in relation to RESISTmin and in relation to the adenosine and acetylcholine maximum flow ratio. For categorized variables, Groups 1 and 2 were compared using Fisher's exact test.

Group comparisons relating to $\mathrm{CBF}, \mathrm{CFV}, \mathrm{CF}, \mathrm{SBP}, \mathrm{DBP}$ and MBP variables throughout baseline and adenosine 1 and 2 dose evaluations were performed using profile analysis. The same analyses were performed for group comparisons throughout baseline and acetylcholine 1, 2, and 3 dose evaluations, baseline and saline evaluations, and baseline and nitroglycerin evaluations. Occasionally, differences observed in hemodynamic variable behaviors (BP and heart rate) in response to vasodilating drugs (adenosine and acetylcholine) were considered in the endothelium-dependent and independent CFR calculation, using a covariance analysis.

The association of LVFS variables with SBP, DBP, MBP, age, LVM, RWT, LVFSS, RESISTmin, CBFRe $i$ and CBFRe $\mathrm{d}$ variables (the latter 2 adjusted by covariance analysis) were evaluated using Pearson's correlation coefficient and multiple linear regression. A stepwise method was adopted to identify variables with an entry significance level equal to 0.10 and an exit equal to 0.05 . Data are expressed as means and standard deviations. $\mathrm{p}<0.05$ was considered significant.

\section{RESULTS}

\section{Demographic and laboratory variables}

No differences were found between groups in terms of age, sex, race, BSA, tabagism, or family history of coronary insufficiency. No difference was identified between groups based on laboratory test results, including total cholesterol level, LDL-cholesterol, HDL-cholesterol, or triglycerides, all of which were within normal ranges. Urea was statistically higher and creatinine tended to be higher in Group 2, but all values were still within the normal ranges (Table 1).

\section{Left ventricle structure and function}

The LVDD $(54.2 \pm 5.9 \mathrm{~mm} \times 69.0 \pm 10.7 \mathrm{~mm}), \mathrm{LVSD}$
$(38.3 \pm 4.4 \mathrm{~mm} \times 57.4 \pm 9.6 \mathrm{~mm})$, LVM $(201.5 \pm 65.7$ $\left.\mathrm{g} / \mathrm{m}^{2} \times 310.4 \pm 99.1 \mathrm{~g} / \mathrm{m}^{2}\right)$, and LVFSS $\left(81.0 \pm 19.910^{3} \mathrm{dyn} /\right.$ $\mathrm{cm}^{2} \times 123.99 \pm 28.1310^{3} \mathrm{dyn} / \mathrm{cm}^{2}$ ) were lower in Group 1, and the RWT $(0.44 \pm 0.1 \times 0.34 \pm 0.1)$ was higher in Group $1(\mathrm{p}<0.05)$. No differences between IVS and PW thickness measurements were identified.

\section{Hemodynamic study}

Aorta root blood pressures were higher in Group 1 compared to Group 2 [systolic $(168.1 \pm 28.5 \mathrm{~mm} \mathrm{Hg} \mathrm{x}$ $136.6 \pm 31.0 \mathrm{~mm} \mathrm{Hg})$, diastolic $(90.6 \pm 11.5 \mathrm{~mm} \mathrm{Hg} \times 75.0$ $\pm 12.3 \mathrm{~mm} \mathrm{Hg})$ and mean $(117.4 \pm 13.7 \mathrm{~mm} \mathrm{Hg}$ x $95.9 \pm$ $15.6 \mathrm{~mm} \mathrm{Hg})](\mathrm{p}<0.05)$. Cardiac index also tended to be higher in Group $1\left(3.3 \pm 0.6 \mathrm{~L} / \mathrm{min} \cdot \mathrm{m}^{2}\right.$ x $\left.2.7 \pm 0.5 \mathrm{~L} / \mathrm{min} \cdot \mathrm{m}^{2}\right)$ $(\mathrm{p}=0.0524) . \mathrm{LV}$ pulmonary capillary, central venous, and final diastolic pressures, pulmonary blood pressure (systolic, diastolic, and median), and systemic and pulmonary vascular resistance rates were not statistically different between groups.

\section{Coronary blood flow}

Intracoronary drug administration was well tolerated. Saline solution infusion did not significantly change the anterior descending coronary artery diameter (Group 1, from $2.98 \pm 0.58$ to $3.00 \pm 0.50 \mathrm{~mm}$; Group 2, from 3.49 \pm 0.34 to $3.54 \pm 0.30 \mathrm{~mm} ; \mathrm{p}=0.2913)$, the coronary blood flow velocity (Group 1, from $23.88 \pm 8.01$ to $25.00 \pm 8.77$ $\mathrm{cm} / \mathrm{sec}$; Group 2, from $21.10 \pm 4.98$ to $22.30 \pm 6.62 \mathrm{~cm} /$ sec; $p=0.0850$ ), heart rate (Group 1, from $73.88 \pm 8.97$ to $72.88 \pm 10.22 \mathrm{bpm}$; Group 2, from $68.40 \pm 9.77$ to $67.70 \pm$ $10.24 \mathrm{bpm} ; \mathrm{p}=0.1712$ ), SBP (Group 1, from $164.88 \pm 25.39$ to $161.50 \pm 26.04 \mathrm{mmHg}$; Group 2, from $130.80 \pm 26.81$ to $131.40 \pm 27.22 \mathrm{mmHg} ; \mathrm{p}=0.2464$ ) and MBP (Group 1, from $121.75 \pm 14.87$ to $118.13 \pm 13.94 \mathrm{mmHg}$; Group 2, from $97.10 \pm 14.41$ to $97.70 \pm 15.38 \mathrm{mmHg} ; \mathrm{p}=0.1551)$. DBP decreased (Group 1, from $91.38 \pm 10.98$ to $88.88 \pm 10.20 \mathrm{~mm}$ $\mathrm{Hg}$; Group 2, from $77.40 \pm 11.47$ to $75.10 \pm 12.02 \mathrm{~mm} \mathrm{Hg}$; $\mathrm{p}=0.0176)$, comparably in both groups $(\mathrm{p}=0.9136)$.

\section{Adenosine coronary blood flow}

Adenosine results are listed in Table 2. Profile analysis showed no differences in heart rate between the groups $(\mathrm{p}=0.2933)$ and no change in the two adenosine dose administrations $(\mathrm{p}=0.3139)$, in either group $(\mathrm{p}=0.2225)$. SBP and MBP were lower in Group 2 ( $\mathrm{p}=0.0207$ and $\mathrm{p}=0.0159$, respectively), while DBP showed no difference between groups $(\mathrm{p}=0.0589)$. No SBP changes occurred in the two adenosine dose administrations at baseline $(\mathrm{p}=0.7207)$ 
Table 2 - Hemodynamic variables, coronary blood flow velocity, and anterior descending coronary artery diameter with the use of adenosine

\begin{tabular}{lll}
\hline Variables & Group 1 & Group 2 \\
\hline HR-Basal (bpm & $73.88 \pm 8.97$ & $68.40 \pm 9.77$ \\
HR-AD1 (bpm) & $74.00 \pm 8.54$ & $69.20 \pm 7.73$ \\
HR-AD2 (bpm) & $73.75 \pm 8.10$ & $71.20 \pm 8.32$ \\
SBP-Basal (mm Hg) & $164.88 \pm 25.39$ & $130.80 \pm 26.81^{*}$ \\
SBP-AD1 (mm Hg) & $162.25 \pm 29.74$ & $130.10 \pm 29.47^{*}$ \\
SBP-AD2 (mm Hg) & $163.63 \pm 26.73$ & $129.40 \pm 29.74^{*}$ \\
DBP-Basal (mm Hg) & $91.38 \pm 10.98$ & $77.40 \pm 11.47$ \\
DBP-AD1 (mm Hg) & $80.13 \pm 11.29^{\#}$ & $68.20 \pm 14.85^{\#}$ \\
DBP-AD2 (mm Hg) & $79.25 \pm 11.88^{\#}$ & $70.10 \pm 17.15^{\#}$ \\
MBP-Basal (mm Hg) & $121.75 \pm 14.87$ & $97.10 \pm 14.41^{*}$ \\
MBP-AD1 (mm Hg) & $111.50 \pm 17.08^{\#}$ & $93.40 \pm 18.77^{* \#}$ \\
MBP-AD2 (mm Hg) & $107.25 \pm 14.62^{\#}$ & $90.40 \pm 18.51^{* \#}$ \\
CFV-Basal (cm/seg) & $23.88 \pm 8.01$ & $21.10 \pm 4.98$ \\
CFV-AD1 (cm/seg) & $62.88 \pm 17.52^{\#}$ & $51.80 \pm 17.89^{\#}$ \\
CFV-AD2 (cm/seg) & $65.25 \pm 20.45^{\#}$ & $51.00 \pm 17.42^{\#}$ \\
D-Basal (mm) & $2.98 \pm 0.58$ & $3.49 \pm 0.34^{*}$ \\
D-AD1 (mm) & $3.10 \pm 0.60^{\#}$ & $3.67 \pm 0.37^{* \#}$ \\
D-AD2 (mm) & $3.21 \pm 0.64^{\#}$ & $3.74 \pm 0.42^{* \#}$ \\
\hline AD1-18 & &
\end{tabular}

$\mathrm{AD} 1=18 \mu \mathrm{g}$ adenosine; $\mathrm{AD} 2=36 \mu \mathrm{g}$ adenosine; $\mathrm{HR}=$ heart rate; $\mathrm{SBP}=$ systolic blood pressure; $\mathrm{DBP}=$ diastolic blood pressure; $\mathrm{MBP}=$ mean blood pressure; $\mathrm{CFV}=$ coronary flow velocity; $\mathrm{D}=$ anterior descending artery diameter; $*=\mathrm{p}<0.05$ vs. group $1 ;{ }^{*}=\mathrm{p}<0.05 \mathrm{vs}$. basal

in either group. DBP and MBP decreased $(\mathrm{p}=0.0005)$ comparably in both groups ( $\mathrm{p}=0.6107$ and $\mathrm{p}=0.1637$ for DBP and MBP, respectively) for both adenosine doses in relation to baseline values. No difference in DBP $(\mathrm{p}=0.8332)$ or MBP $(\mathrm{p}=0.2008)$ were found from the two adenosine dose administrations in either group.

Coronary blood flow velocity did not differ between groups $(\mathrm{p}=0.1715)$ and increased $(\mathrm{p}<0.0001)$ comparably in both groups $(\mathrm{p}=0.2716)$ in relation to baseline values $(\mathrm{p}<0.0001$ for the two adenosine dose administrations). No difference was found in coronary blood flow velocity from the first to the second adenosine dose administrations in either group ( $\mathrm{p}=0.6573$, Figure 1 ).

Anterior descending coronary artery diameter was greater in Group 2 than in Group $1(p=0.0313)$. An increase $(p=0.0005)$ in the anterior descending artery diameter was observed at the two adenosine dose administrations, which was comparable between groups $(p=0.6605)$ compared with baseline values. No difference in the two adenosine dose administrations diameters occurred in either group $(p=0.0734)$. Profile analysis showed that coronary blood flow did not differ between groups and increased comparably

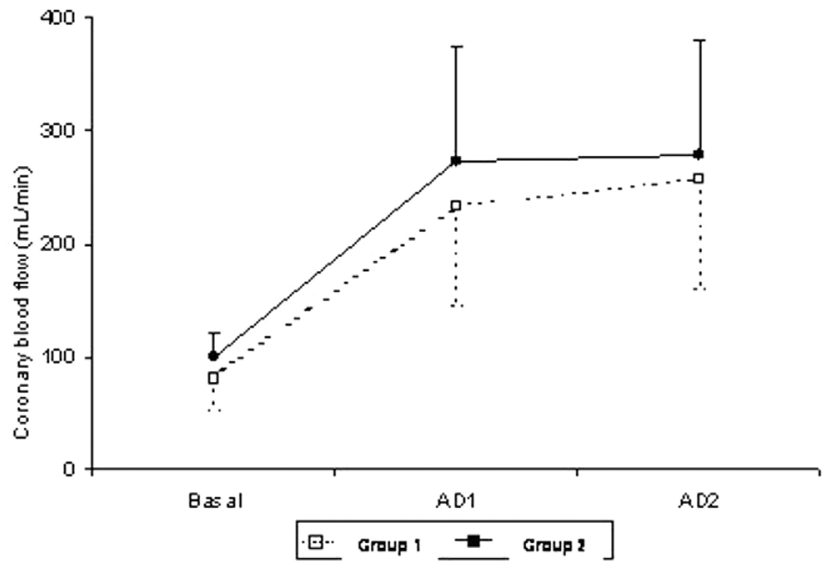

Figure 1 - Effect of intracoronary administration of adenosine (AD1=18 $\mu \mathrm{g}$. AD2 $=36 \mu \mathrm{g}$ ) on coronary blood flow in Groups 1 and 2. Profile analysis showed that coronary blood flow did not differ between groups and increased comparably in relation to baseline values in both. No coronary blood flow difference from the first to the second adenosine dose administrations was evidenced in either group.

in relation to baseline values in both. No coronary blood flow difference from the first to the second adenosine dose administrations was evidenced in either group (Figure 1).

\section{Acetylcholine coronary blood flow}

Acetylcholine results are listed in Table 3. Profile analysis showed that heart rate did not differ between groups $(p>0.05)$ and changed differently in the two groups $(p=0.0498)$. Heart rate at AC3 in relation to baseline values increased in Group 2 ( $p=0.0393$ ), but decreased in Group 1 $(p=0.0270)$. No difference in heart rate from $\mathrm{AC} 1$ to $\mathrm{AC} 2$ $(p=0.08680)$ and from AC2 to AC3 $(p=0.3101)$ occurred in Group 2, while in Group 1, heart rate decreased from AC1 to $\mathrm{AC} 2(p=0.0257)$, and no difference occurred from AC2 to AC3 $(p=0.8835)$.

SBP, DBP, and MBP were lower in Group 2 ( $p=0.0425$, $p=0.0368$, and $p=0.0157$, respectively). No differences in SBP, DBP, and MBP ( $p=0.8104, p=0.2526$, and $p=0.2455$, respectively) occurred with the three acetylcholine dose administrations in relation to baseline values in either group.

Coronary blood flow velocity did not differ between groups $(p=0.4706)$ and increased $(p=0.0061)$ comparably $(p=0.8837)$ in relation to baseline values in both (AC1, $p=0.0167$; AC2, $p=0.0008 ; \mathrm{AC} 3, p=0.0011)$. An increase ( $p=0.0028$ ) from $\mathrm{AC} 1$ to $\mathrm{AC} 2$ also occurred in both groups, and no coronary blood flow velocity difference was identified from $\mathrm{AC} 2$ to $\mathrm{AC} 3$ in any group $(p=0.2583)$.

The anterior descending coronary diameter did not differ between the groups $(p=0.1238)$ and increased $(p=0.0289)$ comparably in both groups $(p=0.6164)$ in relation to 
Table 3 - Hemodynamic variables, coronary blood flow velocity, and anterior descending coronary artery diameter with the use of acetylcholine

\begin{tabular}{|c|c|c|}
\hline Variables & GROUP 1 & GROUP 2 \\
\hline HR-Basal (bpm & $73.88 \pm 8.97$ & $68.40 \pm 9.77$ \\
\hline HR-AC1 (bpm) & $73.88 \pm 8.11$ & $68.70 \pm 8.56$ \\
\hline HR-AC2 (bpm) & $71.13 \pm 10.02^{\alpha}$ & $68.80 \pm 8.50$ \\
\hline HR-AC3 (bpm) & $69.14 \pm 8.25^{\#}$ & $69.22 \pm 9.67^{\#}$ \\
\hline SBP-Basal (mmHg) & $164.88 \pm 25.39$ & $130.80 \pm 26.81^{*}$ \\
\hline SBP-AC1 (mmHg) & $166.75 \pm 23.33$ & $131.70 \pm 31.13^{*}$ \\
\hline SBP-AC2 (mmHg) & $164.25 \pm 26.52$ & $126.90 \pm 39.76^{*}$ \\
\hline SBP-AC3 (mmHg) & $166.00 \pm 27.28$ & $138.11 \pm 28.09^{*}$ \\
\hline DBP-Basal (mmHg) & $91.38 \pm 10.98$ & $77.40 \pm 11.47^{*}$ \\
\hline DBP-AC1 (mmHg) & $92.75 \pm 12.00$ & $77.20 \pm 12.63^{*}$ \\
\hline DBP-AC2 (mmHg) & $89.38 \pm 11.73$ & $73.70 \pm 22.31 *$ \\
\hline DBP-AC3 (mmHg) & $88.71 \pm 9.23$ & $80.22 \pm 12.53^{*}$ \\
\hline MBP-Basal (mmHg) & $121.75 \pm 14.87$ & $97.10 \pm 14.41 *$ \\
\hline MBP-AC1 (mmHg) & $124.50 \pm 14.54$ & $99.50 \pm 17.33^{*}$ \\
\hline MBP-AC2 (mmHg) & $120.13 \pm 14.72$ & $95.40 \pm 27.50 *$ \\
\hline MBP-AC3 (mmHg) & $119.00 \pm 15.09$ & $104.11 \pm 14.90^{*}$ \\
\hline CFV-Basal (cm/seg) & $23.88 \pm 8.01$ & $21.10 \pm 4.98$ \\
\hline CFV-AC1 (cm/seg) & $29.63 \pm 13.61^{\#}$ & $24.80 \pm 10.60^{\#}$ \\
\hline CFV-AC2 (cm/seg) & $41.00 \pm 19.87^{\# \alpha}$ & $30.10 \pm 14.97^{\# \alpha}$ \\
\hline CFV-AC3 (cm/seg) & $43.14 \pm 25.40^{\#}$ & $34.67 \pm 17.45^{\#}$ \\
\hline D-Basal (mm) & $2.98 \pm 0.58$ & $3.49 \pm 0.34$ \\
\hline $\mathrm{D}-\mathrm{AC} 1(\mathrm{~mm})$ & $3.06 \pm 0.72^{\#}$ & $3.62 \pm 0.40^{\#}$ \\
\hline D-AC2 (mm) & $3.03 \pm 0.67^{\#}$ & $3.60 \pm 0.34^{\#}$ \\
\hline $\mathrm{D}-\mathrm{AC} 3(\mathrm{~mm})$ & $3.06 \pm 0.71^{\tau}$ & $3.26 \pm 0.55^{\tau}$ \\
\hline
\end{tabular}

$\mathrm{AC} 1=10^{-7} \mathrm{M}$ acetylcholine; $\mathrm{AC} 2=10^{-6} \mathrm{M}$ acetylcholine; $\mathrm{AC} 3=10^{-5} \mathrm{M}$ acetylcholine; $\mathrm{HR}=$ heart rate; $\mathrm{SBP}=$ systolic blood pressure; $\mathrm{DBP}=$ diastolic blood pressure; $\mathrm{MBP}=$ mean blood pressure; $\mathrm{CFV}=$ coronary flow velocity; $\mathrm{D}=$ anterior descending artery diameter; ${ }^{*}=\mathrm{p}<0.05$ vs. group $1 ;{ }^{*}=\mathrm{p}<0.05$ vs. basal; ${ }^{\alpha}=\mathrm{p}<0.05$ vs. $\mathrm{AC} 1 ;{ }^{\tau}=\mathrm{p}<0.05$ vs. $\mathrm{AC} 2$

baseline values (AC1, $p=0.0261 ; \mathrm{AC} 2, p=0.0434)$. AC3 diameter was comparable with baseline in both groups $(p=0.1211)$. No diameter changes were noted from AC1 to AC2 $(p=0.4530)$. A diameter decrease occurred from AC2 to $\mathrm{AC} 3(p=0.0073)$.

Two patients from Group 1 and four from Group 2 exhibited coronary artery spasms with the highest dose of acetylcholine (AC3). No analysis of these spasms was performed because they occurred in arterial segments that were not included in our measurements for the coronary blood flow calculation. No statistical differences between groups were identified in relation to the occurrence of these spasms.

Profile analysis showed that coronary blood flow did not differ between the groups but increased comparably in both in relation to baseline values. Coronary blood flow also

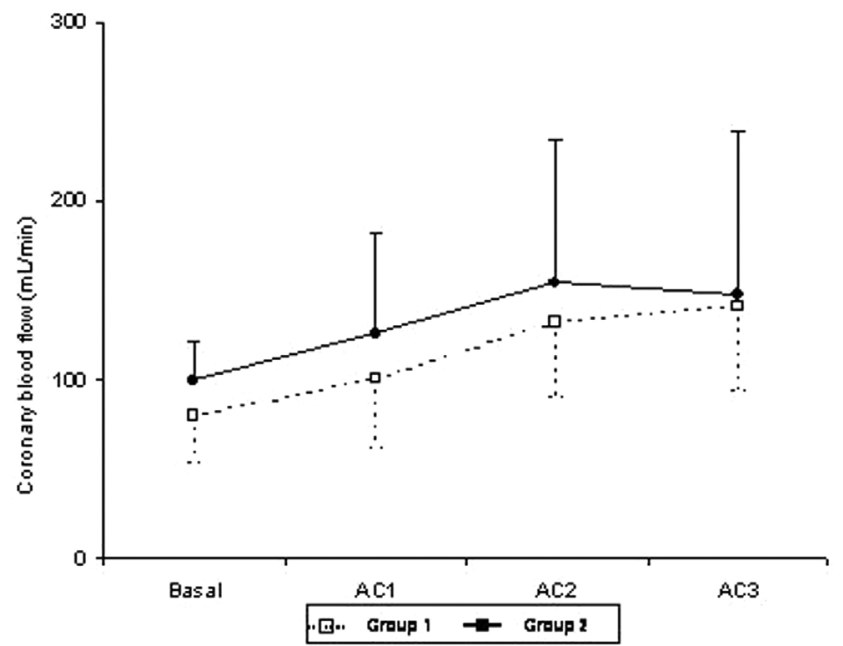

Figure 2 - Effect of intracoronary administration of acetylcholine $\left(\mathrm{AC} 1=10^{-7}\right.$ M. AC2 $=10^{-6} \mathrm{M} . \mathrm{AC} 3=10^{-5} \mathrm{M}$ ) on coronary blood flow in Groups 1 and 2. Profile analysis showed that coronary blood flow did not differ between the groups but increased comparably in both in relation to baseline values. Coronary blood flow also increased between $\mathrm{AC} 1$ and $\mathrm{AC} 2$, but not from $\mathrm{AC} 2$ to $\mathrm{AC} 3$ in any group.

increased between $\mathrm{AC} 1$ and $\mathrm{AC} 2$, but not from $\mathrm{AC} 2$ to $\mathrm{AC} 3$ in any group (Figure 2).

The maximum coronary blood flow ratios using acetylcholine (CBFRm ac) and adenosine (CBFRm ad) were statistically comparable $(p=0.6361)$ between Group $1(0.65$ $\pm 0.27)$ and Group $2(0.60 \pm 0.17)$.

\section{Endothelium-independent coronary blood flow reserve}

As SBP and DBP differed between the groups, endothelium-independent CBFR individual values were adjusted to baseline SBP and DBP values in the covariance analysis (COVAN). No endothelium-independent CBFR difference was seen between groups $(p=0.4652)$.

\section{Endothelium-dependent coronary blood flow reserve}

Individual endothelium-dependent CBFR values were adjusted to baseline SBP and DBP values and were replaced by the difference between maximum and baseline $\mathrm{CF}$ in the covariance analysis (COVAN), as SBP and DBP differed between the groups and $\mathrm{CBF}$ was differently affected in each group. No endothelium-dependent CBFR difference occurred between groups $(p=0.0772)$.

\section{Minimal coronary blood resistance}

RESISTmin did not differ between groups. The mean value for Group 1 was $0.48 \pm 0.21 \mathrm{~mm} \mathrm{Hg} / \mathrm{mL} / \mathrm{min}$, and for Group 2 it was $0.34 \pm 0.12 \mathrm{~mm} \mathrm{Hg} / \mathrm{mL} / \mathrm{min}(p=0.0874)$. 


\section{Nitroglycerin epicardial anterior coronary artery vaso- dilatation}

The anterior descending coronary artery diameter was larger $(p=0.0253)$ in Group 2 (baseline $=3.49 \pm 0.34 \mathrm{~mm}$; $\mathrm{NG}=3.91 \pm 0.36 \mathrm{~mm}$ ) than in Group 1 (baseline=2.9 $8 \pm$ $0.58 \mathrm{~mm} ; \mathrm{NG}=3.35 \pm 0.60 \mathrm{~mm})$ and increased $(p=0.0002)$ comparably ( $p=0.8076$ ) in both groups in relation to baseline values. Profile analysis showed that heart rate increased $(p=0.0244)$, while SBP $(p=0.0122), \operatorname{MBP}(p=0.0035)$, and DBP $(p=0.0118)$ decreased with nitroglycerin administration comparably in both groups.

\section{LV fractional shortening and predictive factors}

Pearson's correlation coefficient values with respective statistical probabilities of the simple linear regression analysis between LVFS and clinical study variables are shown in Table 4. Casual blood pressure measurements (SBP, DBP, MBP) were used in this analysis. A stepwise multiple linear regression analysis identified DBP and LVFSS as variables that were independently correlated to LVFS (adjusted $\mathrm{r}^{2}=0.7109$; DBP $p=0.0045$; LVFSS: $p=0.0002$ ).

Table 4 - Pearson's linear correlation between LVFS and study variables

\begin{tabular}{lcc}
\hline Variables & $\mathrm{r}$ & $\mathrm{p}$ \\
\hline SBP & 0.51 & 0.0299 \\
DBP & 0.58 & 0.0114 \\
MBP & 0.57 & 0.0137 \\
Age & 0.01 & 0.9797 \\
LVM & -0.40 & 0.1037 \\
RWT & 0.68 & 0.0018 \\
LVFSS & -0.75 & 0.0004 \\
RESISTmin & 0.26 & 0.3007 \\
CBFRe i & 0.60 & 0.0137 \\
CBFRe d & 0.37 & 0.1257 \\
\hline
\end{tabular}

$\mathrm{SBP}=$ systolic blood pressure; $\mathrm{DBP}=$ diastolic blood pressure; $\mathrm{MBP}=$ mean blood pressure; $\mathrm{LVM}=$ indexed left ventricular mass; RWT=relative wall thickness; LVFSS=LV end-systolic stress; CBFRe i=coronary blood flow reserve, endothelium independent; CBFRe $\mathrm{d}=$ coronary blood flow reserve, endothelium dependent.

\section{DISCUSSION}

Our study included hypertensive patients without other risk factors for heart disease (with the exception of one smoker). This study design allowed us to evaluate to the extent possible the independent effect of hypertension on CBFR. Although the study population consisted of patients with hypertensive heart disease who had been prescribed significant quantities of hypertensive medication, all were within NYHA functional classes I or II. In order to reduce the influence of hypertensive drugs on our results, all such medications were withheld for 24 to 48 hours before the study, as is common practice in the literature. ${ }^{3,5,6,8}$ It is widely accepted that one should wait 5 half-lives to eliminate the effects of a given drug - for some of the drugs used, 5 half-lives was longer than our chosen suspension duration. However, because our patients were at risk of hemodynamic decompensation, we did not consider it ethically acceptable to withhold their medications for an extended period.

Groups were assigned based on LV systolic function with statistically equivalent demographic and laboratory variables, and can therefore be considered comparable. However, echocardiographic evaluation confirmed a higher grade of LV remodeling and LV dysfunction in Group 2 compared to Group 1.

\section{Hemodynamic characteristics}

Hemodynamic variables confirmed the good clinical compensation status of the patients, as filling pressures and cardiac index were at acceptable levels. We also note that no patients exhibited pulmonary artery hypertension. Groups did not differ in respect of ventricular filling pressures, a variable that could interfere with coronary blood flow measurements. The difference in LV afterload was evident because higher pressure levels were obtained at the aortic root in Group 1. The ultimate impact of CBFR in the context of this perfusion difference was not observed during the RESISTmin calculation, because no differences were identified between groups.

\section{Coronary blood flow reserve}

We chose to use nitroglycerin at the end of the study to evaluate whether the epicardial coronary artery response to an endothelium-independent stimulus was preserved. Therefore, in the event this arterial segment did not respond to flow induced by microcirculation dilation, we could conclude that it did not occur due to an inability of the vessel's medium layer to respond to a vasodilatation stimulus, but rather due to a deficiency in the endothelium response to the increase in shear stress. Furthermore, as we observed, intracoronary nitroglycerin induces significant systemic hemodynamic alterations, such as a decrease in $\mathrm{BP}$ and an increase in heart rate, a fact that may interfere with CBF measurements. We performed isolated saline infusion, with a documented absence of measurable effects that supported the reliability of our results. 
Our data suggest that endothelium-dependent and endothelium-independent CBFR vasodilator administrations were similar in patients with normal or decreased LV systolic function. Other studies have shown differences in endothelium-dependent and independent CBFR in cases of hypertension ${ }^{3,6}$ and dilated cardiomyopathy. ${ }^{5}$ In hypertension, the CBF dynamic is more dependent on structural than functional vascular alterations. It should be noted that the ratio between the maximum flow obtained with acetylcholine and that recorded with adenosine, an indication of endothelial function, was comparable in both study groups and was similar to normal values described in the literature. ${ }^{3,15}$ Additionally, the increase in epicardial diameter of the anterior descending coronary artery with adenosine was comparable between groups, reinforcing a similarity in endothelial function. Because adenosine acts primarily on vessel resistance, ${ }^{16}$ the induced diameter increase is understood to derive from high shear stresses consistent with an increased CBF, mediated by the endothelium. ${ }^{8,17}$ This occurs even when an epicardial artery diameter measurement taken when adenosine is used is recorded synchronously with a microcirculation action peak (15 to 20 seconds). The necessary waiting time for maximum flow-dependent vasodilatation response is 50 to 60 seconds, as demonstrated in humans. ${ }^{18}$ However, it is possible that a greater interval between adenosine administration and the documentation of epicardial coronary artery diameter could lead to different results.

The responses obtained with nitroglycerin show that conductance vessel vasodilatation capacity was comparable in both groups and was preserved, similar to previous reports. ${ }^{19}$ This normal vasodilatation response to nitroglycerin indicates a preserved epicardial coronary artery structure.

These results do not support the hypothesis that ischemic alterations caused by endothelial dysfunction explain LV functional maladaptation in hypertensive heart disease. Other studies have shown that hypertension, in the absence of other risk factors, is not associated with coronary endothelial dysfunction. ${ }^{3,15}$

Interestingly, although the two groups did not differ in endothelium-independent CBFR, there was a positive correlation with LVFS. In other words, the higher the ventricular dysfunction, the lower the reserve. However, this correlation was not evidenced in the multivariate analysis. The inverse correlation between LV systolic function and LVFSS was previously described in the context of hypertensive heart disease.$^{20}$ In our study, LVFSS represented one of two variables independently related to LVFS. It is well known that one of the strongest coronary blood flow determinants is myocardial oxygen intake. Although CBFR does not correlate with LVFS in the multiple linear regression model given LVFSS and DBP variables, one must consider that, when facing an increase in systolic stress, the CBFR may be inadequate for the increased myocardial oxygen intake. Thus, if CBFR is not a determining factor for systolic dysfunction, its reduction may contribute to the continuation and/or aggravation of this clinical condition. This study shows that an association also exists between DBP and LV systolic function. The observed BP decrease in Group 2 can be explained in terms of deteriorating ventricular function.

It is important to emphasize that the study population consisted of hypertensive patients undergoing adequate long-term clinical treatment. It is possible that including patients who had not previously undergone treatment would have yielded different results. Antihypertensive drug treatment, particularly with calcium channel antagonists, ${ }^{21,22}$ angiotensin-converting enzyme inhibitors, ${ }^{23}$ and angiotensinreceptor blockers, ${ }^{24}$ can positively interfere with endothelial function and vascular remodeling. However, this fact does not diminish the significance of our findings. By contrast, it provides new perspectives for understanding how hypertension treatment can positively impact disease evolution.

\section{Study limitations}

In this study, we did not use a normal control group, because this does not exist in practice, and it did not seem ethical to use an invasive methodology to conduct a characterization. In the literature, control groups consist of normal heart and angina patients with microcirculation disease (Syndrome X). ${ }^{25}$ We emphasize, however, that the values we obtained for endothelium-dependent and independent CBFR are very close to those reported in many studies. ${ }^{3,6,17}$

\section{ACKNOWLEDGMENTS}

We thank Julia T. Fukushima for performing the statistical analysis.

\section{REFERENCES}

1. Levy D, Garrison RJ, Savage DD, Kannel WB, Castelli WP. Prognostic implications of echocardiographically determined left ventricular mass in the Framingham Heart Study. N Engl J Med 1990;322:1561-6.
2. Frolich ED. Risk mechanismsin hypertensive heart disease. Hypertension 1999;34:782-9. 
3. Hamasaki S, Suwaidi JA, Higano ST, Miyauchi K, Holmes DR Jr, Lerman A. Attenuated coronary flow reserve and vascular remodeling in patients with hypertension and left ventricular hypertrophy. J Am Coll Cardiol 2000;35:1654-60.

4. Antony I, Nitenberg A, Foult J-M, Aptecar E. Coronary vasodilator reserve in untreated and treated hypertensive patients with and without left ventricular hypertrophy. J Am Coll Cardiol 1993;.22:514-20.

5. Treasure CB, Vita JA, Cox DA, Fish RD, Gordon JB, Mudge GH, et al. Endothelium-dependent dilatation of the coronary microvasculature is impaired in dilated cardiomyopathy. Circulation 1990;81:772-9.

6. Treasure CB, Klein JL, Vita JA, Manoukian SV, Renwick GH, Selwyn AP, et al. Hypertension and left ventricular hypertrophy are associated with impaired endothelium-mediated relaxation in human coronary resistance vessels. Circulation 1993;87:86-93.

7. The 7th Report of the Joint National Committee on Prevention, Detection, Evaluation and Treatment of High Blood Pressure - JNC VII. JAMA 2003;289:1560-72 .

8. Duffy SJ, Castle SF, Harper RW, Meredith MB. Contribution of prostanoids and nitric oxide to resting flow, metabolic vasodilatation, and flow-mediated dilatation in human coronary circulation. Circulation 1999;100:1951-7.

9. Lang RM, Bierig M, Devereux RB, Flachskampf FA, Foster E, Pellikka PA, et al. Recommendations for chamber quantification: a report from the American Society of Echocardiography's Guidelines and Standards Committee and the Chamber Quantification Writing Group, developed in conjunction with the European Association of Echocardiography, a branch of the European Society of Cardiology.. J Am Soc Echocardiogr 2005;18(12):1440-63.

10. Troy BL, Pombo J, Rackley CE. Measurement of left ventricular wall stress and mass by echocardiography. Circulation 1972;45:602-11.

11. Reichek N, Wilson J, St John-Suton M, Plappert TA, Goldberg S, Hirshfeld JW. Noninvasive determination of left ventricular systolic stress: validation of the method and initial application. Circulation 1982;65:99-108.

12. Ganz W, Swan HJC. Measurement of blood flow by thermodilution. Am J Cardiol 1972;29:241-6.

13. Doucette JW, Corl PD, Payne HM, Flynn AE, Goto M, Nassi M, et al. Validation of a Doppler guide wire for intravascular measurement of coronary artery flow velocity. Circulation 1992;85:1899-911.

14. Reddy KG, Nair RN, Sheehan HM, Hodgson JM. Evidence that selective endothelial dysfunction may occur in the absence of angiographic or ultrasound atherosclerosis in patients with risk factors for atherosclerosis. J Am Coll Cardiol 1994;23:833-43.
15. Zeiher AM, Drexler H, Saurbier B, Just H. Endothelium-mediated coronary blood flow modulation in humans. Effects of age, atherosclerosis, hypercholesterolemia, and hypertension. J Clin Invest 1993;92:652-62.

16. Wilson RF, Wyche K, Christensen BV, Zimmer S, Laxson DD. Effects of adenosine on human coronary arterial circulation. Circulation 1990;82:1595-606

17. Reis SE, Holubkov R, Lee JS, Sharaf B, Reichek N, Rogers WJ, et al; for the WISE Investigators. Coronary flow velocity responses to adenosine characterizes coronary microvascular function in women with chest pain and no obstructive coronary disease. Results from the pilot phase of the Women's Ischemia Syndrome Evaluation (WISE) Study. J Am Coll Cardiol 1999;33:1469-75.

18. Hollenberg SM, Tamburro P, Johnson MR, Burns DE, Spokas D, Costanzo MR, et al. Simultaneous intracoronary ultrasound and Doppler flow studies distinguish flow-mediated from receptor-mediated endothelial responses. Cathet Cardiovasc Intervent 1999;46:282-8.

19. Feldman RL, Marx JD, Pepine CJ, Conti CR. Analysis of coronary responses to various doses of intracoronary nitroglycerin. Circulation $1982 ; 66: 321-327$

20. Strauer BE. The coronary circulation in hypertensive heart disease. Hypertension 1984;6(suppl):74-80.

21. Schiffrin EL, Pu Q, Park JQ. Effect of amlodipine compared to atenolol on small arteries of previously untreated essential hypertensive patients. Am J Hypertens 2002;15:105-10.

22. Bracht C, Yan XW, Brunner-LaRocca HP, Sutsch G, Amann FW, Kiowski W. Isradipine improves endothelium-dependent vasodilation in normotensive coronary artery disease patients with hypercholesterolemia. J Hypertens 2001;19:899-905.

23. Mancini GB, Henry GC, Macaya C, O'Neill BJ, Pucillo AL, Carere RG, et al. Angiotensin-converting enzymeinhibition with quinapril improves endothelial vasomotor dysfunction in patients with coronary artery disease: the TREND (Trial on Reversing ENdothelial Dysfunction) study. Circulation 1996;94:258-65.

24. Kamezaki F, Tasaki H, Yamashita K, Shibata K, Hirakawa N, Tsutsui $\mathrm{M}$, et al. Angiotensin receptor blocker improves coronary flow velocity reserve in hypertensive patients: comparison with calcium channel blocker. Hypertens Res 2007;30(8):699-706.

25. Bottcher M, Botker HW, Sonne H, Nielsen TT, Czernin J. Endotheliumdependent and -independent perfusion reserve and the effect of $\mathrm{L}$-arginine on myocardial perfusion in patients with syndrome $\mathrm{X}$. Circulation 1999;99:1795-801. 
